\title{
Picture Archiving and Communication System in Hokkaido University Hospital: Advantage and Disadvantage of HU-PACS Chest Roentgenogram Images in the Outpatient Clinic
}

\author{
Kenji Miyamoto, Shosaku Abe, and Yoshikazu Kawakami
}

\begin{abstract}
A new Hokkaido University picture achiving and communication system (HU-PACS) has been in clinical use in the outpatient clinic at HU Hospital. To evaluate the quality of the cathode-ray tube (CRT) monitor images, we compared the detectability of line shadows in the chest roentgenogram images on the CRT monitor with those on the computed radiography (CR) film. We randomized chest roentgenograms from 20 patients who were admitted to the outpatient clinic with pulmonary disease. Two physicians, whose speciality is chest roentgenogram diagnosis, checked whether they could recognize a horizontal fissure line (hairline) on the posteroanterior view and a minor fissure line and major fissure lines on the lateral view. Only $30 \%$ of hairlines were recognized on CRT monitor as compared with $65 \%$ on CR film. On the lateral view, only $68 \%$ of major fissures and $53 \%$ of minor fissures on CRT monitor were recognized as compared with $89 \%$ and $79 \%$, respective on CR film. Furthermore, it was somewhat difficult to follow entire lines on some of the CRT monitor images. Clinically, the greatest advantage of the PACS is immediate availability of images, including chest roentgenogram, chest computed tomography (CT) and magnetic resonance imaging (MRI). PACS is also convenient for consulting colleagues in other departments. Unfortunately, the quality of the image on the CRT monitor is not yet good enough to visualize line shadows and small solitary lesions on the chest roentgenogram image. Recent advances in high technology have been so rapid, however, that higher resolution CRT monitors will be available soon.
\end{abstract}

Copyright (C) 1991 by W.B. Saunders Company

KEY WORDS: PACS, computed radiography, image quality.

$\mathbf{R}^{\mathrm{E}}$ ECENT ADVANCES in computed radiography $(\mathrm{CR})$ have made it possible to convert the analog data of the chest roentgenogram image to digital data, and to develop Hokkaido University picture archiving and communication system (HU-PACS). In the first step, conventional radiographies were converted to $\mathrm{CR}$ to derive

From the 1st Department of Medicine, Hokkaido University School of Medicine, Sapporo, Japan.

Address reprint requests to Kenji Miyamoto, $M D, 1$ st Department of Medicine, Hokkaido University School of Medicine, Sapporo 060, Japan.

Copyright (c) 1991 by W.B. Saunders Company

0897-1889/91/0404-0109\$03.00/0 digital image data; thereafter, we developed PACS, in cooperation with NEC. The HU-PACS was initiated in June 1, 1989, and is now used in the outpatient clinics of general medicine, orthopedics, and radiology. There are 16 image display terminals (IDTs) in the hospital, and seven of them are in daily use in general medicine outpatient clinics. In this article, we introduce a simple operation of the IDT and discuss advantages and disadvantages of this system in our clinic.

\section{COMPOSITION OF THE IDT}

The IDT consists of four elements: a monitor, a main unit for image processing, a keyboard, and a mouse (Fig 1). The cathode ray tube (CRT) monitor is a 20 -inch monochrome monitor with 1066 scanning lines and has a matrix that is 1536 $\times 1024$. The main unit of image processing has a main memory of 16 Mbyte for image data and a hard disk unit of 80 Mbyte, which can save at least 160 chest roentgenogram images one-tenth compressed. The keyboard generally is not used except to input a password to start the system and to input the patient's identification (ID) number to search for the image. The mouse is used to control and process the image data once it has been transported to the terminal unit.

\section{OPERATION OF THE SYSTEM}

It takes about 30 to 60 seconds to transport image data from the host computer. Once the data are saved in the IDT hard disk unit, roentgenogram, computed tomography (CT), and magnetic resonance imaging (MRI) scans, which are one-half the size of the original, appear in less than 10 seconds. We can handle each image processing very easily and quickly.

\section{Image Processing}

At all times, a 4-command menu is open on the upper right corner of the screen (Fig 2); including (1) a magnification tool with which we can magnify the IDT image of roentgenogram, 
High resolution CRT monitor

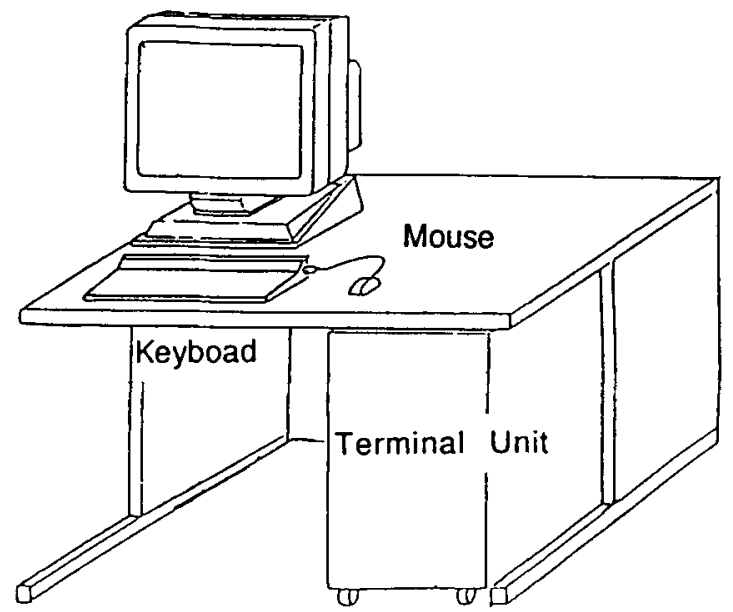

Fig 1. Image display terminal.

CT, and MRI 10 times by moving the mouse to the right or reduce it by moving the mouse to the left; a window tool, with which we can change the level of the window by moving the mouse vertically and the width of the window by moving the mouse horizontally; an image processing tool, which when selected causes another menu to appear on the left side of the screen (Fig 3); and screen division, which allows us to select singleor double-screen image (each double image is controlled independently).
Once menus have been selected by choice of the image processing tool, they disappear automatically, so that they do not interfere with or obscure the image.

The menus include:

1. Image processing

(1) Gamma-characteristic

(2) Rotation

(3) Edge enhancement

(4) Measurement, ie, angles and distances

2. Search, by which we can search for an image by patient's name, modality, date, or region of the body.

3. Other tools

(1) Next image

(2) Previous image

(3) Original image; even if we change the image on the screen, we are able to call up the original image.

(4) Save

(5) Delete

(6) Help

(7) Quit (Shut down)

\section{COMPARISON OF CHEST ROENTGENOGRAM} IMAGE ON CRT WITH CR FILM

The matrix of $\mathrm{CR}$ film is more than 2000 $\times 2000$, and the same image of the CRT monitor is $1024 \times 1024$. Therefore, the quality of the CRT image clearly is worse than that of CR film. We
Fig 2. Chest roentgenogram image and image processing tool menu on the CRT monitor.

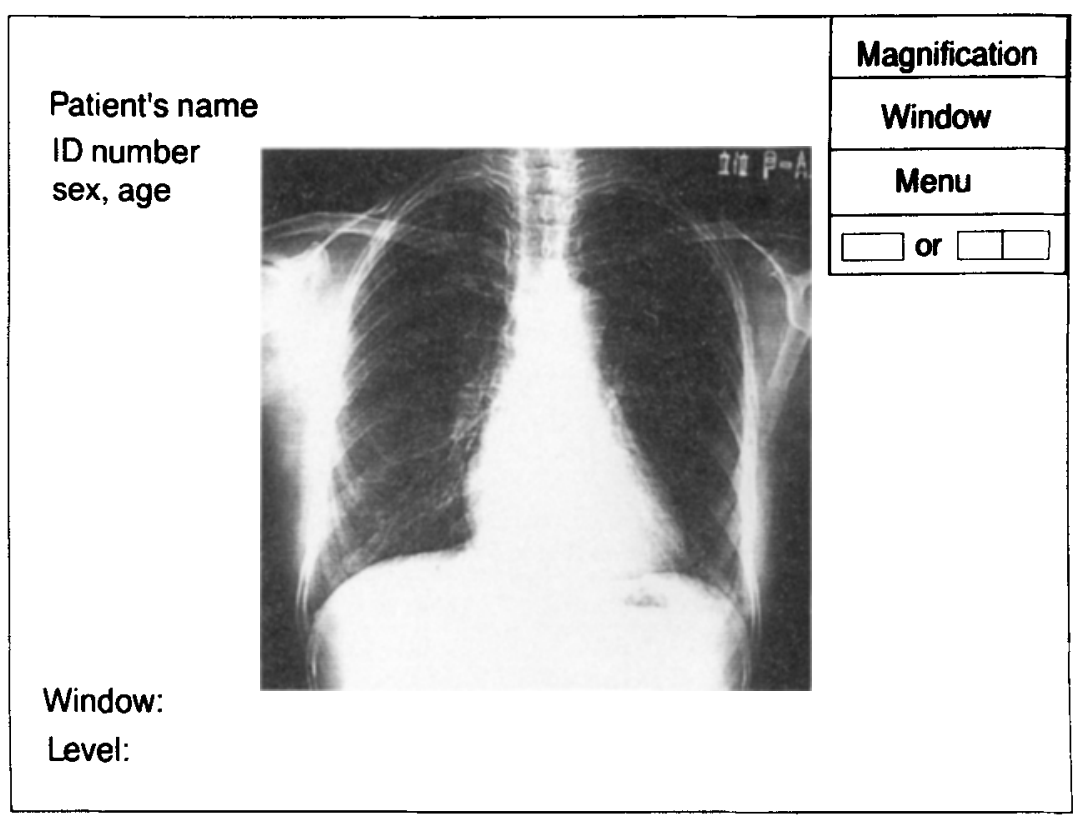




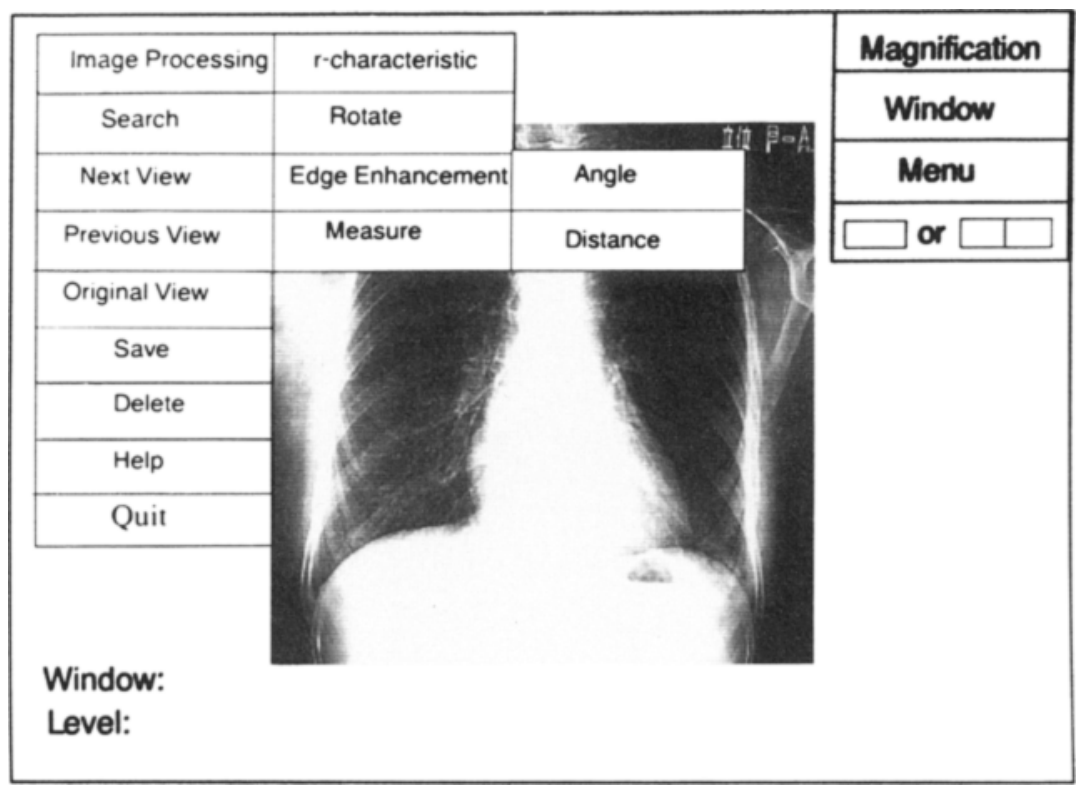

Fig 3. Image processing menu on the CRT monitor. wished to determine whether we could recognize the difference of image quality with the naked eye without using the magnification function of the terminal.

We randomized chest roentgenograms from 20 patients who were referred to the outpatient clinic of the pulmonary disease department. Two physicians, whose speciality is chest roentgenogram diagnosis, determined whether they could recognize a horizontal fissure line (hairline) on the posteroanterior view, and a minor fissure line and major fissure lines on the lateral view.

Table 1 shows that only $30 \%$ of hairlines could be recognized on the CRT monitor as compared with $65 \%$ on CR film. On the lateral view, only $68 \%$ of major fissures and $53 \%$ of minor fissures on CRT monitor were recognized as compared with $89 \%$ and $79 \%$ on CR film, respectively. In addition, following entire lines in some of the CRT monitor images was somewhat difficult. Poor detection of line shadows on the CRT mon-

Table 1. Detectability of Line Shadows

\begin{tabular}{lcc}
\hline \multicolumn{1}{c}{ View } & FCR Film & CRT Monitor \\
\hline $\begin{array}{l}\text { Posteroanterior } \\
\text { Horizontal fissure (hairline) }\end{array}$ & $13 / 20(65 \%)$ & $6 / 20(30 \%)$ \\
$\begin{array}{l}\text { Lateral } \\
\quad \text { Major fissure }\end{array}$ & $17 / 19(89 \%)$ & $13 / 19(68 \%)$ \\
Minor fissure & $15 / 19(79 \%)$ & $10 / 19(53 \%)$ \\
\hline
\end{tabular}

itor image is a critical disadvantage when diagnosing bullae, pneumothorax, lung solitary lesions, pneumonia, or atelectasis.

We also checked sharpness and clarity of small coin lesions in chest roentgenograms of two patients, one with lung cancer and one with pulmonary metastasis from stomach cancer. We compared the number of metastatic lesions we could find on the CR film with the number we could find on the CRT monitor (Table 2). In the image to patient 1 , we detected 7 small coin lesions on the CR film, but only 5 lesions on the CRT monitor were detected. In the image of patient 2, we found 9 metastatic small lesions on the CR film, but only 5 lesions on the CRT monitor. Even after we used the technique of edge enhancement, the results were the same.

OTHER ADVANTAGE OF PACS IN CLINICAL USE

The main advantages of PACS are rapid search and easy comparison owing to double images on the screen. With the split screen, it is also very

Table 2. Detection of Small Coin Lesions on Chest Roentgenogram Images

\begin{tabular}{lcc}
\hline \multirow{2}{*}{ Patient } & \multicolumn{2}{c}{ No. of Small Coin Lesions } \\
\cline { 2 - 3 } & FCR Film & CRT Monitor \\
\hline 1 (Lung cancer) & 7 & 5 \\
2 (Stomach cancer) & 9 & 5 \\
\hline
\end{tabular}


helpful to call up the chest roentgenogram with typical or reference abnormal lesions and compare it with the patient's image.

\section{CONCLUSIONS}

Clinically the greatest advantage of the PACS is immediate availability of images, including chest roentgenograms, chest $C T$, and MRI. PACS is also convenient for consultations with colleagues from other departments. Unfortunately, the quality of the image on the CRT monitor is not yet good enough to distinguish line shadows or small solitary lesions on the chest roentgenogram image. However, advances in high technology are so rapid that a higher resolution CRT will soon be available.

\section{REFERENCES}

1. Tateno Y, Inamura T, Takano M. Computed Radiography. Springer-Verlag, Tokyo, 1987

2. Miyasaka $\mathrm{K}$, Irie $\mathrm{G}$, Kawakami $\mathrm{Y}$, et al: PACS in the Hokkaido University Hospital. Med Imaging Technol 6:159160,1988 